\title{
Article \\ Using Systems Thinking and Modelling: Ecological Land Utilisation Efficiency in the Yangtze Delta in China
}

\author{
Chunmei Zhang ${ }^{1,2, *(\mathbb{D})}$, Ziwen Feng ${ }^{1}\left(\mathbb{D}\right.$, Qilong Ren ${ }^{1,2}$ and Wei-Lng Hsu ${ }^{1,2, *(\mathbb{C})}$ \\ 1 School of Urban and Environmental Science, Huaiyin Normal University, Huai'an 223300, China; \\ 1000511983@smail.shnu.edu.cn (Z.F.); 8201811022@hytc.edu.cn (Q.R.) \\ 2 Key Research Base of Philosophy and Social Sciences of Colleges \& Universities in Jiangsu Province, \\ Research Institute of Huai River Eco-Economic Belt, Huai'an 223300, China \\ * Correspondence: 8199701017@hytc.edu.cn (C.Z.); 8201811011@hytc.edu.cn (W.-L.H.); \\ Tel.: +86-15189653701 (C.Z.); +86-15751385380 (W.-L.H.)
}

check for updates

Citation: Zhang, C.; Feng, Z.; Ren, Q.; Hsu, W.-L. Using Systems Thinking and Modelling: Ecological Land Utilisation Efficiency in the Yangtze Delta in China. Systems 2022, 10, 16 https://doi.org/10.3390/ systems10010016

Academic Editor: William T. Scherer

Received: 19 January 2022

Accepted: 10 February 2022

Published: 13 February 2022

Publisher's Note: MDPI stays neutral with regard to jurisdictional claims in published maps and institutional affiliations.

Copyright: (C) 2022 by the authors. Licensee MDPI, Basel, Switzerland. This article is an open access article distributed under the terms and conditions of the Creative Commons Attribution (CC BY) license (https:// creativecommons.org/licenses/by/ $4.0 /)$.

\begin{abstract}
Ecological land has two definitions: the broad category and the narrow category. This paper studied the narrow category, which refers to the land whose main purpose is to provide ecological services, such as environmental regulation and biological conservation. Ecological land areas are likely to decrease with the development of urbanisation all over the world, which poses potential risks to the environment, society, and public health, and low utilisation efficiency of ecological land will exacerbate this risk. Based on the actual input-output situation of ecological land utilisation, we constructed an index system in the Yangtze Delta to measure the ecological land utilisation efficiency with a Slack-Based Model (SBM) in the data envelopment analysis (DEA). The results revealed that the comprehensive efficiency exhibited an increasing trend from 2012 to 2020, and more high-efficiency cities appeared in the areas closer to Shanghai. Both the technical efficiency and scale efficiency increased over the research period. The technical efficiencies in most cities were efficient and equal to the scale efficiencies. Among the remaining cities, the technical efficiencies and scale efficiencies were inefficient and not synchronous. In addition, we found that the that poor efficiencies of some cities can mainly be attributed to low-technology, an unsuited-scale, or a combination of these. In the future, improvement should be focused on the economical and intensive use of ecological land, technical innovations, and the optimal scale. The present results can provide references for making scientific decisions regarding the efficient utilisation of ecological land in the Yangtze Delta and other similar rapid-urbanization areas.
\end{abstract}

Keywords: sustainable urbanization; ecological land; utilisation efficiency; DEA-SBM; the Yangtze Delta

\section{Introduction}

Rapid urbanisation and industrialisation worldwide have contributed to the expansion of construction land and the shrinkage of ecological land with ecological regulation functions [1-4]. This exacerbates global damage to ecosystems [5-9] and causes ecological security concerns $[10,11]$. Urbanisation is one of the most transformative trends in the 21st century [12]. With the growth of urban populations and economies, urban entities have expanded their land area and spatial scope.

The main causes are the differences in the land rent prices between urban and rural areas, the profit seeking nature of capital $[13,14]$, and the personal choices of the middle class $[15,16]$. Urban renewal caused by traffic improvement, especially the installation or expansion of public transport facilities, which is making rapid progress in more advanced European countries and being prepared for in other countries, promotes urban expansion.

With economic recovery and prosperity in the post-COVID-19 period, urban renewal activities may expand rapidly [17]. Urbanisation is the inevitable product of economic development and technological advancement. It promotes the rapid development of human civilization and the rapid growth of social material and spiritual wealth. However, 
urbanisation has also brought some negative effects regarding human and environmental well-being. These include water pollution and food security [12], air pollution that spreads many diseases including COVID-19 [18], loss and fragmentation of biological habitats [19] etc. pose challenges to human sustainable development goals, especially in developing economies, such as India, Vietnam, Sri Lanka, the Philippines, and Indonesia [12].

In the fast-growing Great Bay Area (GBA) of Guangdong, Hong Kong, and Macao in China, there is sufficient evidence that urbanisation leads to a general decline in natural habitats and ecosystem services, such as water conservation, soil conservation, and carbon sequestration [20]. These side effects of urbanisation will affect or even hinder the further development of human civilization.

Many programmes have been implemented to reduce or offset the side effects of urbanisation. From the perspective of urban planning, the 15-Minute Life Cycle [21] and Superblock Street Networks [22] with walking [18] or cycling have been increasingly used all over the world. From the perspective of industrial adjustment, the adjustment from productive industries to producer services to reduce export pollution has also achieved successful results in some cities, such as Bilbao in Spain [23].

From the perspective beyond the city, some countries and regions, such as the United States [24], the European Union [25], and China [26], have attached importance to ecological land utilisation outside the city to deal with the resource and environmental problems caused by urbanisation. The implementation of these programs can alleviate the negative impacts caused by urbanisation in different ways.

In 1997, the American Environmental Monitoring and Assessment Program began monitoring the status of ecological land in the United States [24]. Since the beginning of the 21st century, various regions in developing countries, including the Mumbai Metropolitan Region in India [27], Mekong Delta in Vietnam [28], and Southeast Region in Brazil [29], have been faced with the reduction of ecological land, which makes various sectors gradually pay increased attention to the sustainability of ecological lands [1,30-33]. In the Millennium Ecosystem Assessment Reports published in 2005, the United Nations Environment Programme stressed the importance of the active participation of countries worldwide in the sustainable development and governance of ecological land [25].

The European Union's 7th Environment Action Programme published in 2012 also highlighted the importance of increasing land resource utilisation efficiency while maintaining the sustainable development of ecological land [34]. In 2018, China identified ecological civilisation as its new national strategy for sustainable development [26]. In the meantime, scholars all over the world also performed scientific research on the sustainable utilisation of ecological land from various perspectives and achieved many meaningful results.

Ecological land is a critical resource. It has social functions (e.g., providing resources and assets to society) and ecosystem service functions (e.g., regulating and improving regional environmental quality) [35-37]. In the 1990s, Klijn et al. began to study ecological land and its classification [38]. Ecological land was referred to as land resources capable of providing material products or factors while offering ecological regulation services in studies by Yang and Gao et al., and the examples they provided of such land included farmland, woodland, wetland, grassland, and waters $[39,40]$.

The pattern of change of a specific ecological land type, namely forests [41], grasslands [42], and wetlands [43], were investigated by Watson et al., Zhang et al., and Hansen et al., and the overall pattern of change of all ecological land types was examined by An [44]. Different scholars defined the connotation of ecological land according to different research objectives, and there were certain differences in accounting the scope of ecological land due to the different levels of land division standards used.

Ecological land has multiple functional values, and its ecosystem service value has attracted particular attention. Guo et al. and Wang et al. evaluated the green benefits of water resources and the ecological security of forests, respectively [45,46]. Scholars, including Wang et al., Wang et al., and $\mathrm{Hu}$ et al., examined the ecosystem service value of land and how changes of urban land use affect ecosystem services $[8,31,47]$. The comprehensive 
value of ecological land is another area that merits attention. Scholars put forward evaluation frameworks of comprehensive value of ecological land from multiple perspectives.

On the basis of the relationship between agriculture and soil stability, Scott proposed a framework for evaluating the values of a farmland system's material production service and environmental regulation service functions; the framework was used to analyse the functional values of land resources and the repulsive relationship between the two functions [48]. Straton established an evaluation framework for the complex functions of ecological land on the basis of the land's intrinsic quality and the subjective evaluation of consumers [49].

On this basis, scholars continued to deeply explore the factors affecting the comprehensive value of ecological land and the action law of influencing factors. From the perspective of system dynamics, Mäler studied the material production and environmental regulation services of lakes and identified dynamic factors and mechanisms affecting the provision of such services [50]. The above research found that there was a contradictory and unified relationship between the multiple functional values of ecological land, which needs to be handled appropriately in order to ensure the efficient work of the functional value of ecological land.

Improving the utilisation efficiency of ecological land is key to maintaining its function and sustainability. Zhang et al. and Gao et al. evaluated the utilisation efficiency of water resources [51,52]; Zhou et al. and Zhu et al. assessed the utilisation efficiency of farmland and all lands, respectively, and analysed temporospatial patterns of change in them $[53,54]$. Data envelopment analysis (DEA), a method commonly used to evaluate efficiency, facilitates effective analysis of the relative efficiency of various types of decision units with multiple inputs and outputs [55].

The DEA model has undergone constant revision for efficiency measurements under various conditions $[1,7,30,56-58]$. Among many efficiency evaluation methods, the DEA model is a method with objectivity, convenience, and clear social significance that providing management information for competent departments. In this paper, SBM with undesired outputs in DEA will be used for corresponding research.

The aforementioned studies predominantly investigated ecological land from the perspectives of conception, classification, functional value, and the utilisation efficiency of single ecological land types. Little research has been conducted on the overall utilisation efficiency of all ecological land types in a region, and no effective evaluation method has been established for said efficiency. In this study, by taking the Yangtze Delta as a case study, the objective law of ecological land utilisation efficiency was investigated.

The primary goals of this study are to (1) explore the temporospatial characteristics of the comprehensive efficiency of ecological land utilisation; (2) determine the characteristics of technical efficiency and scale efficiency, as well as their relations; and (3) reveal the causes of low utilisation efficiency of ecological land and propose accurate measures for the improvement of utilisation efficiency. The evaluation of the utilisation efficiency of ecological land is expected to provide a scientific basis for making adaptation and mitigation strategies in the Yangtze Delta and other regions with similar ecological land shrinkage characteristics. Figure 1 displays the technical routes of the study. 


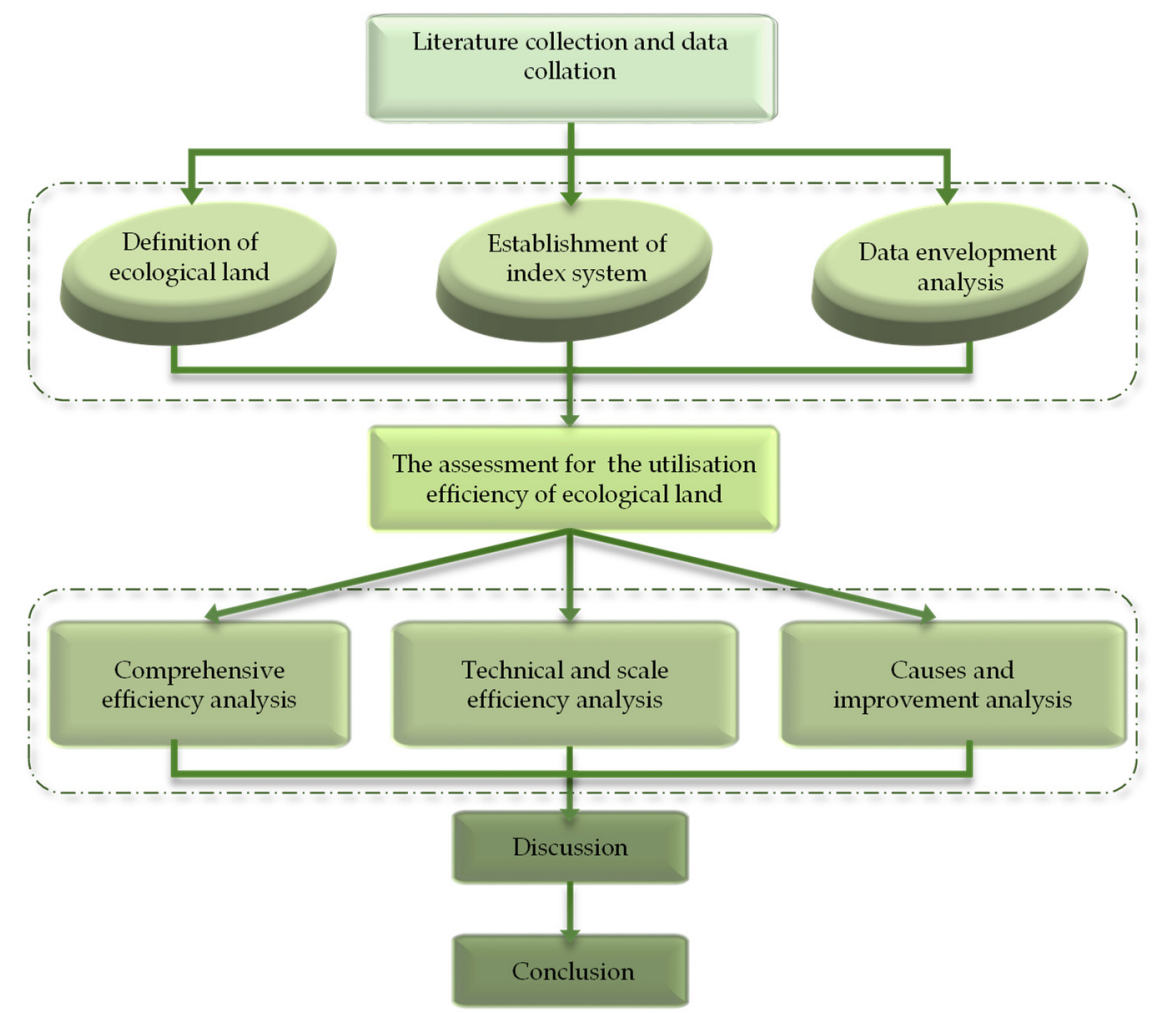

Figure 1. Technical routes of this study.

\section{Methods and Materials}

\subsection{Study Area}

According to the Outline of the Yangtze Delta Regional Integrated Development Plan released in 2019 by the State Council of the People's Republic of China [59], the regional development plan encompassed Shanghai, Jiangsu, Zhejiang, and Anhui. The study area comprises all 41 prefecture-level cities in Shanghai, Jiangsu, Zhejiang, and Anhui (Figure 2).

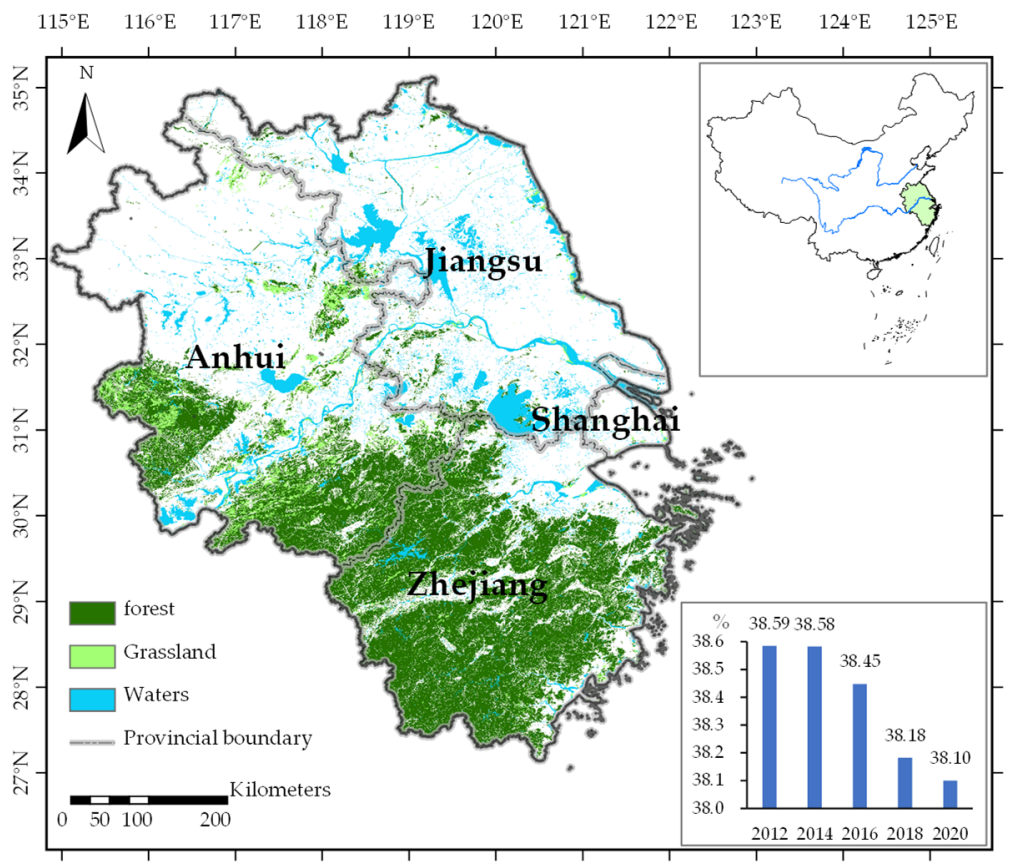

Figure 2. Location and ecological land condition of the Yangtze Delta. 
The Yangtze Delta is among the most economically active and innovative regions in China and of great importance to national development with high quality. However, rapid development has caused the already-small ecological land in this region-such as forest, grassland, and waters - to shrink further. Currently, the total area of forest, grassland, and waters in the Yangtze Delta is approximately 1322 ha, accounting for $38.10 \%$ of all land types. Approximately 997 ha are forest, distributed mainly in the south of the Yangtze Delta. Approximately 110 ha are grassland distributed mostly in the southwest. Approximately 215 ha are waters, found mainly on the banks of the Yangtze River. Research into how ecological land utilisation, such as for forest, grassland, and waters, can be heightened is vital for the region's development.

\subsection{Methodology}

\subsubsection{Definition of Ecological Land Utilisation}

Ecological land has two definitions: the broad category and the narrow category. This paper studied the narrow category, which refers to land whose main purpose is to provide ecological services, such as environmental regulation and biological conservation, and emphasizes the integrity of its spatial structure and the comprehensiveness of its ecological service functions. This study referred to the definition of $\mathrm{Yu}$ et al. for ecological land: a land type that primarily provides ecosystem service functions in a region, accompanied by auxiliary production functions [60,61].

The main types of such land include forest, grassland, and waters [62]. Abandoned farmland $[63,64]$ that can provide ecosystem service functions was generally classified as cultivated land that primarily provides production functions supplemented by ecosystem service functions [40], and thus it was not included in the research scope of this paper. Given the dual functions of ecological land, namely its social and ecosystem service functions, the land's utilisation efficiency must be heightened to boost socioeconomic development while a virtuous circle in the ecological system is maintained.

\subsubsection{Evaluation Indicator System for Ecological Land Utilisation Efficiency}

Based on the definition of ecological land, according to the construction framework of indicator systems in data envelopment analysis (DEA), this study established a system of input indicators from the perspectives of ecological land, labour, and capital as well as a system of desirable and undesirable output indicators from economic, social, and environmental perspectives (Table 1). In the process of ecological land utilisation, the ecological land, labour, and capital as the input side are the natural material carrier, the means, and the socio-economic resource, respectively.

Table 1. System of evaluation indicators for the ecological land utilisation efficiency.

\begin{tabular}{|c|c|c|c|c|}
\hline \multicolumn{2}{|c|}{ Indicator Type } & Indicator Attribute & Indicator Component & Measurement Indicator \\
\hline \multirow{5}{*}{\multicolumn{2}{|c|}{ Input indicator }} & \multirow{3}{*}{ Ecological land input } & Forest & Total area of forest $\left(\mathrm{km}^{2}\right)$ \\
\hline & & & Grassland & Total area of grassland $\left(\mathrm{km}^{2}\right)$ \\
\hline & & & Waters & Total area of waters $\left(\mathrm{km}^{2}\right)$ \\
\hline & & Labour input & Labour & $\begin{array}{l}\text { Number of people working on } \\
\text { ecological land }(10,000 \text { people) }\end{array}$ \\
\hline & & Capital input & Capital & $\begin{array}{c}\text { Amount of fixed capital } \\
\text { investment (100 million RMB) }\end{array}$ \\
\hline \multirow{4}{*}{ Output indicator } & \multirow{3}{*}{ Desirable indicator } & Economic output & Product & $\begin{array}{l}\text { Gross domestic product } \\
(100 \text { million RMB })\end{array}$ \\
\hline & & Social output & Townspeople & Urbanisation rate (\%) \\
\hline & & Ecological service output & Water quality & BCWQI \\
\hline & Undesirable indicator & Ecological pollution output & Air pollutant & $\mathrm{PM}_{2.5}$ concentration $\left(\mu \mathrm{g} / \mathrm{m}^{3}\right)$ \\
\hline
\end{tabular}


Economic development, social progress, and environmental protection as the output side are the three pillars of human sustainable development [65]. Ecological land input comprises forest, grassland, and water inputs; these were measured using their respective total areas. Labour and capital inputs were measured, respectively, using the number of individuals whose jobs involve developing, producing, or managing such land and the amount of fixed capital investment into such land. The number of people working on ecological land was obtained by deducting the number of people in the labour force engaged in farming from the number of people in the rural labour force in the corresponding statistical yearbook.

The amount of fixed capital investment refers to the workload and the changes of related expenses of building and purchasing fixed assets on ecological land over a period of time. This was obtained after the conversion of two variables: the amount of fixed capital investment in the statistical yearbook and the proportion of ecological land area. Economic, social, ecological service, and ecological pollution outputs were measured using the gross domestic product, urbanisation rate, Blue City Water Quality Index (BCWQI), and particulate matter $2.5\left(\mathrm{PM}_{2.5}\right)$, respectively. The economic, social, and ecological service outputs were desirable outputs, and the ecological pollution output was undesirable [33].

The Blue City Water Quality Index (BCWQI) was developed by the Institute of Public and Environmental Affairs to measure the water quality; surface water accounts for $50 \%$ of the water quality score, drinking water $30 \%$, and groundwater $20 \%$ [66].

\subsubsection{DEA}

DEA is an approach to measuring the relative efficiency of Decision Making Units (DMU) with multiple inputs and outputs [55,67]. According to the proposed indicator system, this study selected the slack-based measure model, which considers undesirable outputs, to measure the comprehensive efficiency, technical efficiency, and scale efficiency of ecological land in the Yangtze Delta. The comprehensive efficiency is the efficiency at the overall level, which is mainly composed of the technical efficiency and scale efficiency. Among these, technical efficiency refers to the efficiency affected by production management and technology, and scale efficiency refers to the efficiency affected by the production scale.

Let $X_{j}=\left(x_{1 j}, x_{2 j}, \ldots, x_{m j}\right)^{T}$ be the input indicator, $Y_{j}^{d}=\left(y_{1 j}^{d}, y_{2 j}^{d}, \ldots, y_{k j}^{d}\right)^{T}$ be the desirable output indicator, and $Y_{j}^{u}=\left(y_{1 j}^{u}, y_{2 j}^{u}, \ldots, y_{l j}^{u}\right)^{T}$ be the undesirable output; where $x_{i j}$ denotes the $i$ th input indicator for the $j$ th decision unit, $i=1,2, \ldots, m ; y_{a j}^{d}$ is the $a$ th desirable output indicator for the $j$ th decision unit, $a=1,2, \ldots, k$; and $y_{b j}^{u}$ is the $b$ th undesirable output indicator for the $j$ th decision unit, $b=1,2, \ldots, l$. The equation [68] is as follows:

$$
\left\{\begin{aligned}
\min \theta_{s t e} & =\frac{1-\frac{1}{m} \sum_{i=1}^{m} s_{i j}^{-} / x_{i j 0}}{1+\frac{1}{k+l}\left(\sum_{a=1}^{k} s_{a j}^{d} / y_{a j 0}^{d}+\sum_{b=1}^{l} s_{b j}^{u} / y_{b j 0}^{u}\right)} \\
& \text { s.t. } \\
& \sum_{j=1}^{n} X_{j} \lambda_{j}+s_{j}^{-}=\theta_{s t e} X_{j 0} \\
& \sum_{j=1}^{n} Y_{j} \lambda_{j}-s_{j}^{d}=Y_{j 0}^{d} \\
& \sum_{j=1}^{n} Y_{j} \lambda_{j}+s_{j}^{u}=Y_{j 0}^{u} \\
& \lambda_{j} \geq 0, s_{j}^{-} \geq 0, s_{j}^{d} \geq 0, s_{j}^{u} \geq 0
\end{aligned}\right.
$$




$$
\left\{\begin{array}{c}
\min \theta_{t e}=\frac{1-\frac{1}{m} \sum_{i=1}^{m} s_{i j}^{-} / x_{i j 0}}{1+\frac{1}{k+l}\left(\sum_{a=1}^{k} s_{a j}^{d} / y_{a j 0}^{d}+\sum_{b=1}^{l} s_{b j}^{u} / y_{b j 0}^{u}\right)} \\
\text { s.t. } \\
\sum_{j=1}^{n} X_{j} \lambda_{j}+s_{j}^{-}=\theta_{t e} X_{j 0} \\
\sum_{j=1}^{n} Y_{j} \lambda_{j}-s_{j}^{d}=Y_{j 0}^{d} \\
\sum_{j=1}^{n} Y_{j} \lambda_{j}+s_{j}^{u}=Y_{j 0}^{u} \\
\sum_{i=1}^{n} \lambda_{j}=1 \\
\lambda_{j} \geq 0, s_{j}^{-} \geq 0, s_{j}^{d} \geq 0, s_{j}^{u} \geq 0 \\
\theta_{s e}=\frac{\theta_{s t e}}{\theta_{t e}}
\end{array}\right.
$$

where $\theta_{s t e}, \theta_{t e}$, and $\theta_{s e}$ denote the comprehensive, technical, and scale ecological land utilisation efficiency of $\mathrm{DMU}_{j 0}$, respectively; values closer to 1 indicate higher efficiency.

Continuing, $s_{j}^{-}$is the input redundancy of $\mathrm{DMU}_{j 0}$-that is, the superfluous input part that reaches effective comprehensive efficiency or technical efficiency of $\mathrm{DMU}_{j 0} ; s_{j}^{d}$ is the desirable output deficiency of $\mathrm{DMU}_{j 0}$ - that is, the insufficient desirable output part that reaches effective comprehensive efficiency or technical efficiency of $\mathrm{DMU}_{j 0} ; s_{j}^{u}$ is the undesirable output excess of $\mathrm{DMU}_{j 0}$ - that is, the excess undesirable output part that reaches effective comprehensive efficiency or technical efficiency of $\mathrm{DMU}_{j 0}$; and $\lambda_{j}$ is the peer weight of $\mathrm{DMU}_{j 0}$. If $\sum_{j=1}^{n} \lambda_{j}=1$, then $\mathrm{DMU}_{j 0}$ is constant returns to scale; if $\sum_{j=1}^{n} \lambda_{j}<1$, then $\mathrm{DMU}_{j 0}$ is increasing returns to scale; and if $\sum_{j=1}^{n} \lambda_{j}>1$, then $\mathrm{DMU}_{j 0}$ is decreasing returns to scale [69].

\subsubsection{Classification of Comprehensive Efficiency}

A unified categorisation criteria was formulated to classify the ecological land utilisation efficiency. Ecological land was determined to have a high utilisation efficiency if its comprehensive efficiency was equal to 1 ; it had medium utilisation efficiency if its comprehensive efficiency was equal to or greater than 0.8 and less than 1 ; and poor utilisation efficiency was indicated if its comprehensive efficiency was less than 0.8 (Table 2).

Table 2. Classification and standards of comprehensive efficiency.

\begin{tabular}{cc}
\hline Order and Degree & Categorisation Criteria of Comprehensive Efficiency \\
\hline High efficiency & DEA $=1$ \\
Medium efficiency & $0.8 \leq \mathrm{DEA}<1$ \\
Poor efficiency & $\mathrm{DEA}<0.8$ \\
\hline
\end{tabular}

\subsubsection{Classification of Relationship between Technical Efficiency and Scale Efficiency}

First, cities were grouped into two types according to whether their technical utilisation efficiency for ecological land was equal to or less than 1 . They were then divided according to the scale efficiency (i.e., equal to or less than 1). Subsequently, they were grouped into three types according to whether their technical efficiency was greater than, equal to, or lower than their scale efficiency. Finally, six types of technical efficiency-scale efficiency relationships were established (Table 3).

\subsection{Data Sources}

Data for the ecological land inputs were collected from National Earth System Science Data Centre's data sharing platform; these data were interpretation results of Landsat-7 ETM+ (National Aeronautics and Space Administration, Washington, DC, USA) images and had a resolution of $30 \mathrm{~m} . \mathrm{PM}_{2.5}$ data for the output indicator [70] were obtained from 
each city's ecological environment report for the corresponding year, and BCWQI data were sourced from open data available on the Blue Map app. Data for all the other indicators were collected from each city's statistical yearbook.

Table 3. Types established based on the relationship between technical and scale efficiency.

\begin{tabular}{cc}
\hline Type & \multicolumn{1}{c}{ Criterion } \\
\hline I & Technical efficiency $=$ scale efficiency $=1$ \\
II & Technical efficiency $=1>$ scale efficiency \\
III & Technical efficiency $<$ scale efficiency $=1$ \\
IV & Technical efficiency $=$ scale efficiency $<1$ \\
V & $1>$ technical efficiency $>$ scale efficiency \\
VI & Technical efficiency $<$ scale efficiency $<1$ \\
\hline
\end{tabular}

\section{Result Analysis}

\subsection{Analysis of the Comprehensive Utilisation Efficiency of Ecological Land in the Yangtze Delta}

According to (1), MaxDEA Ultra7 (Beijing revomidi Software Co., Ltd., Beijing, China) was used to calculate the comprehensive ecological land utilisation efficiency of all 41 cities in the Yangtze Delta from 2012 to 2020. Then, the results were deeply analysed from the three dimensions of temporal change, spatial differentiation, and temporospatial change to explore the objective law of ecological land utilisation efficiency in the Yangtze Delta at the comprehensive level.

\subsubsection{Analysis of Temporal Changes}

The average efficiency of all 41 cities in the region was taken as the comprehensive efficiency of ecological land utilisation in the Yangtze Delta, the average efficiency of 13 cities in the province was taken as the comprehensive efficiency of the ecological land utilisation in Jiangsu Province, the average efficiency of 11 cities in the province was taken as the comprehensive efficiency of ecological land utilisation in Zhejiang Province, and the average efficiency of 16 cities in the province was used as the comprehensive efficiency of ecological land utilisation in Anhui Province. The above calculated data and the comprehensive efficiency of ecological land utilisation in Shanghai were summarized and visualised, and the results are shown in Figure 3.

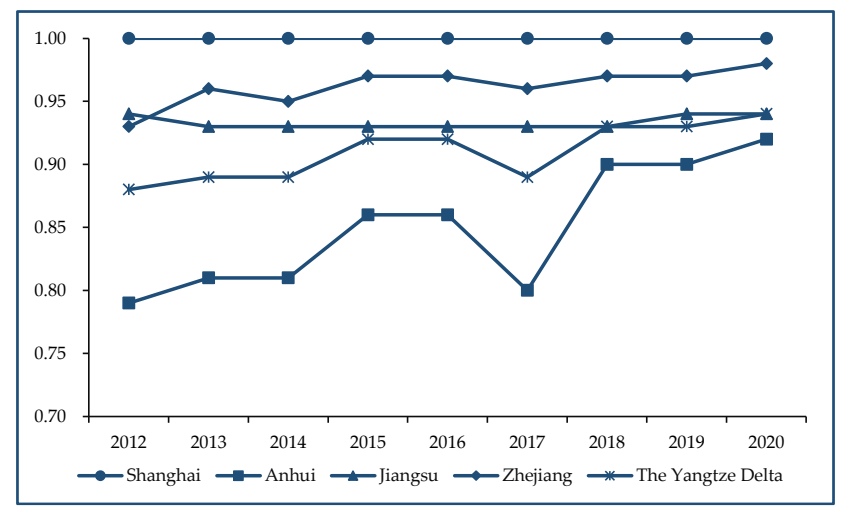

Figure 3. Comprehensive utilisation efficiencies of ecological land in the Yangtze Delta and its provinces from 2012 to 2020 .

According to Figure 3, the comprehensive utilisation efficiency of ecological land in the Yangtze Delta was generally high and exhibited an increasing trend with fluctuations. The average comprehensive efficiency of the Yangtze Delta equalled or exceeded 0.88 throughout and increased from 0.88 in 2012 to 0.94 in 2020, with a temporary drop in 2017. Among the four provincial-level administrative divisions, the comprehensive efficiency 
values of Shanghai, Zhejiang, and Jiangsu were higher than or equal to the average of the Yangtze Delta, whereas that of Anhui was lower than the average.

The comprehensive efficiency of Shanghai remained the highest throughout, followed by Zhejiang, whose comprehensive efficiency increased gradually throughout the period. Jiangsu's comprehensive efficiency was third highest and remained so. Anhui, despite having the lowest comprehensive efficiency, saw a rapid increase in efficiency. Located in the centre of China's east coast where the Yangtze River enters the sea, Shanghai has been at the connection between China's economy and the world economy. With abundant capital, advanced technology, and advanced concepts, the comprehensive efficiency of the ecological land utilisation in Shanghai has been high.

Jiangsu and Zhejiang are coastal provinces adjacent to Shanghai. With their own superior resources and Shanghai's radiation effect, the comprehensive efficiency of ecological land utilisation in Jiangsu and Zhejiang followed that of Shanghai. Anhui, which is far from Shanghai, is an inland province along the Yangtze River. Due to its own lack of development and slow acceptance of Shanghai's radiation effect, the comprehensive efficiency of ecological land utilisation in Anhui was low.

\subsubsection{Spatial Differentiation Analysis}

Following the classification standards of comprehensive efficiency, all 41 cities were classified into different categories according to the comprehensive utilisation efficiency of their ecological land in 2020. The results were then visualised using ArcGIS10.5 (GeoScene Information Technology Co., Ltd., Beijing, China) as shown in Figure 4.

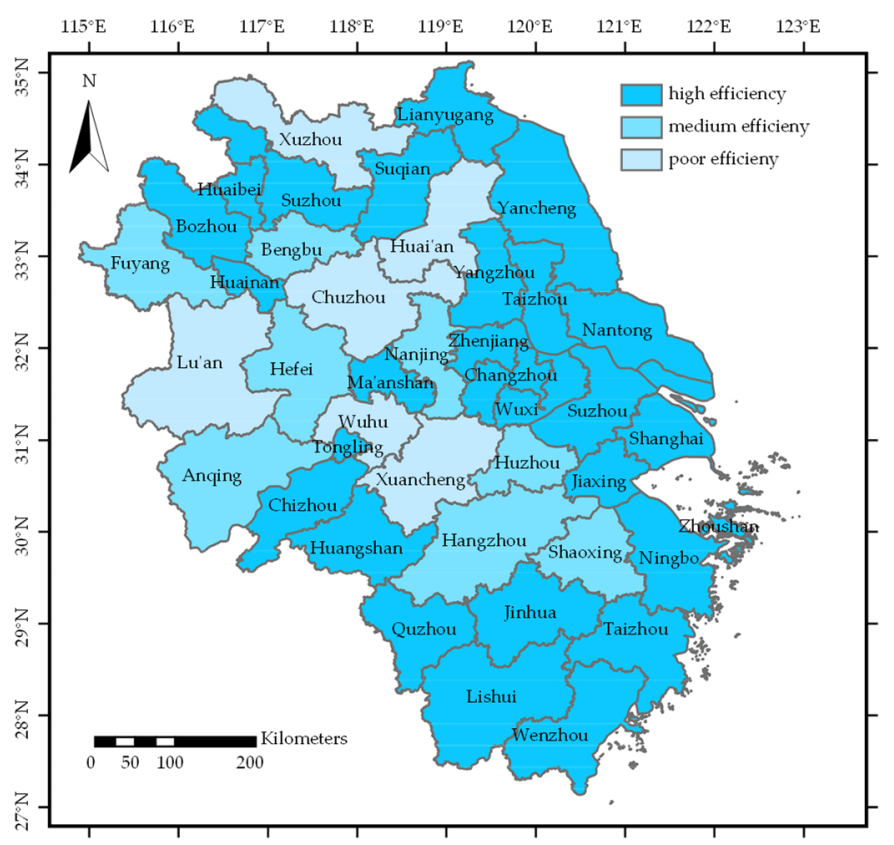

Figure 4. Spatial distribution of the comprehensive efficiency of ecological land utilisation in the Yangtze Delta in 2020.

According to Figure 4, the comprehensive ecological land utilisation efficiency in the Yangtze Delta was categorised as high, medium, or poor. Cities with high efficiency were Shanghai, Lianyungang, Suqian, Yancheng, Yangzhou, and Taizhou (in Jiangsu Province); Nantong, Zhenjiang, Changzhou, Wuxi, and Suzhou (in Jiangsu Province); Jiaxing, Zhoushan, Ningbo, and Taizhou (in Zhejiang Province); and Jinhua, Quzhou, Lishui, Wenzhou, Huangshan, Chizhou, Tongling, Ma'anshan, Huainan, Bozhou, Huaibei, and Suzhou (in Anhui Province).

Cities with medium efficiency were Nanjing, Huzhou, Hangzhou, Hefei, Bengbu, Fuyang, Anqing, and Shaoxing. Those with poor efficiency were Xuzhou, Huai'an, 
Chuzhou, Lu'an, Wuhu, and Xuancheng. Cities with high efficiency were generally distributed in Shanghai and its surrounding areas. Cities with poor efficiency were generally observed in Anhui and in the north of Jiangsu.

\subsubsection{Analysis of Temporospatial Changes}

The comprehensive ecological land utilisation efficiency of the cities in 2012, 2014, 2016, 2018, and 2020 were determined as the corresponding categories according to the same categorisation criteria above. The results were also visualised using ArcGIS10.5, as depicted in Figure 5.

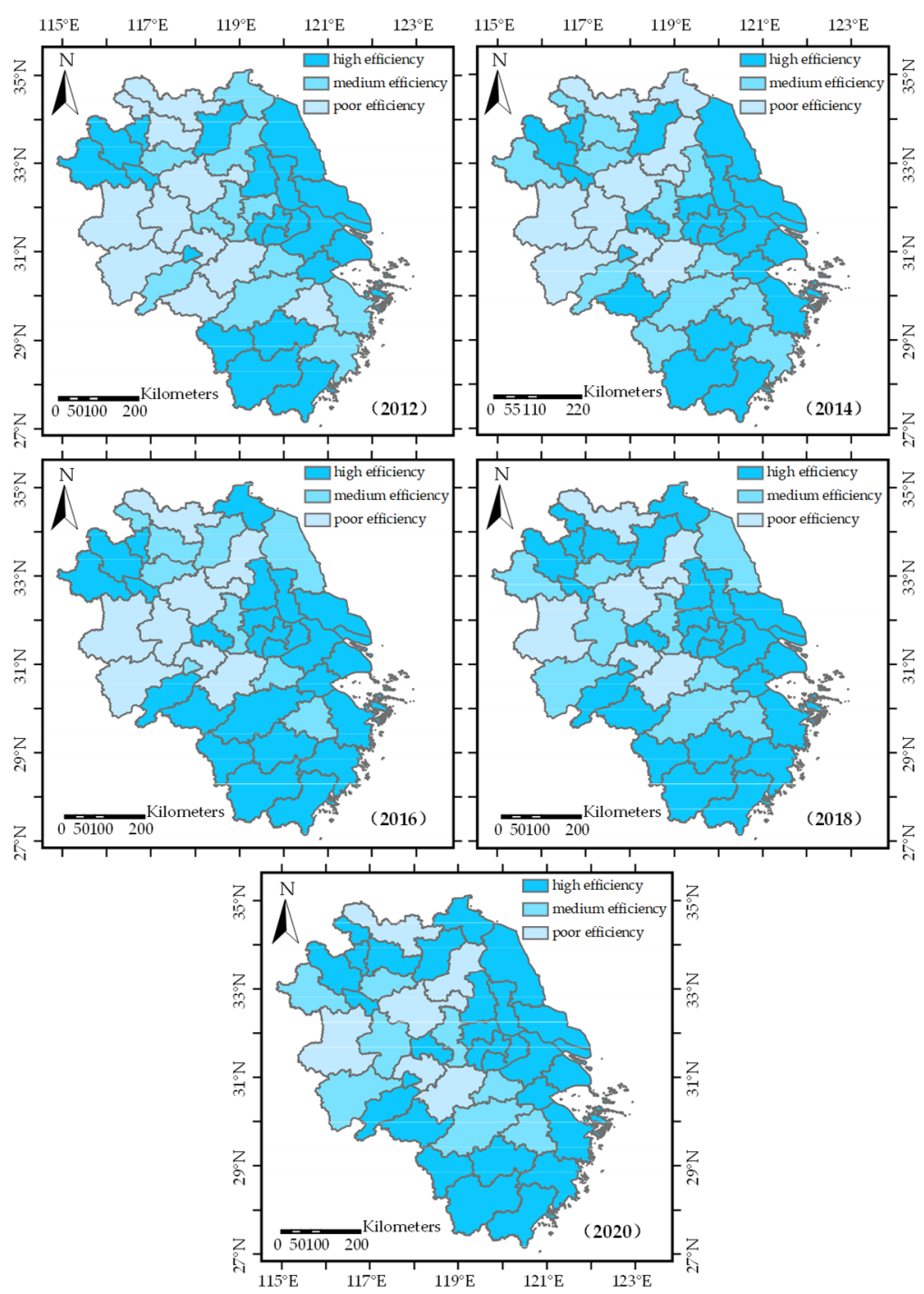

Figure 5. Spatial distribution changes in comprehensive utilisation efficiency of ecological land in the Yangtze Delta from 2012 to 2020.

As shown in Figure 5, the comprehensive efficiency of ecological land utilisation in the Yangtze Delta exhibited an increasing trend overall, with cities differing in their variation of efficiency. The number of cities with high comprehensive ecological land utilisation efficiency increased from 20 to 27; that of medium-efficiency cities decreased from 11 to 8; and that of poor-efficiency cities also decreased from 10 to 6 .

Lianyungang, Zhengjiang, Anqing, Ma'anshan, and Suzhou (in Anhui Province); Huangshan, Chizhou, Hefei, and Taizhou (in Zhejiang Province); Ningbo, Shaoxing, and Quzhou had increasing comprehensive efficiency; Huai'an exhibited a decreasing trend of 
comprehensive efficiency; and the comprehensive efficiency of Chuzhou, Lu'an, Xuancheng, Wuhu, and Xuzhou remained low.

\subsection{Analysis of the Technical and Scale Dimensions of Ecological Land Utilisation Efficiency in the Yangtze Delta}

To further understand how ecological land utilisation efficiency had changed at the technical level and scale level, this study divided said efficiency into technical efficiency and scale efficiency to analyse the spatiotemporal changes of the two separately as well as the relationship between them.

\subsubsection{Analysis of Technical Efficiency}

Equation (2) and MaxDEA Ultra7 were used to calculate the technical utilisation efficiency of ecological land for all 41 cities in the Yangtze Delta. Figure 6 presents the results.

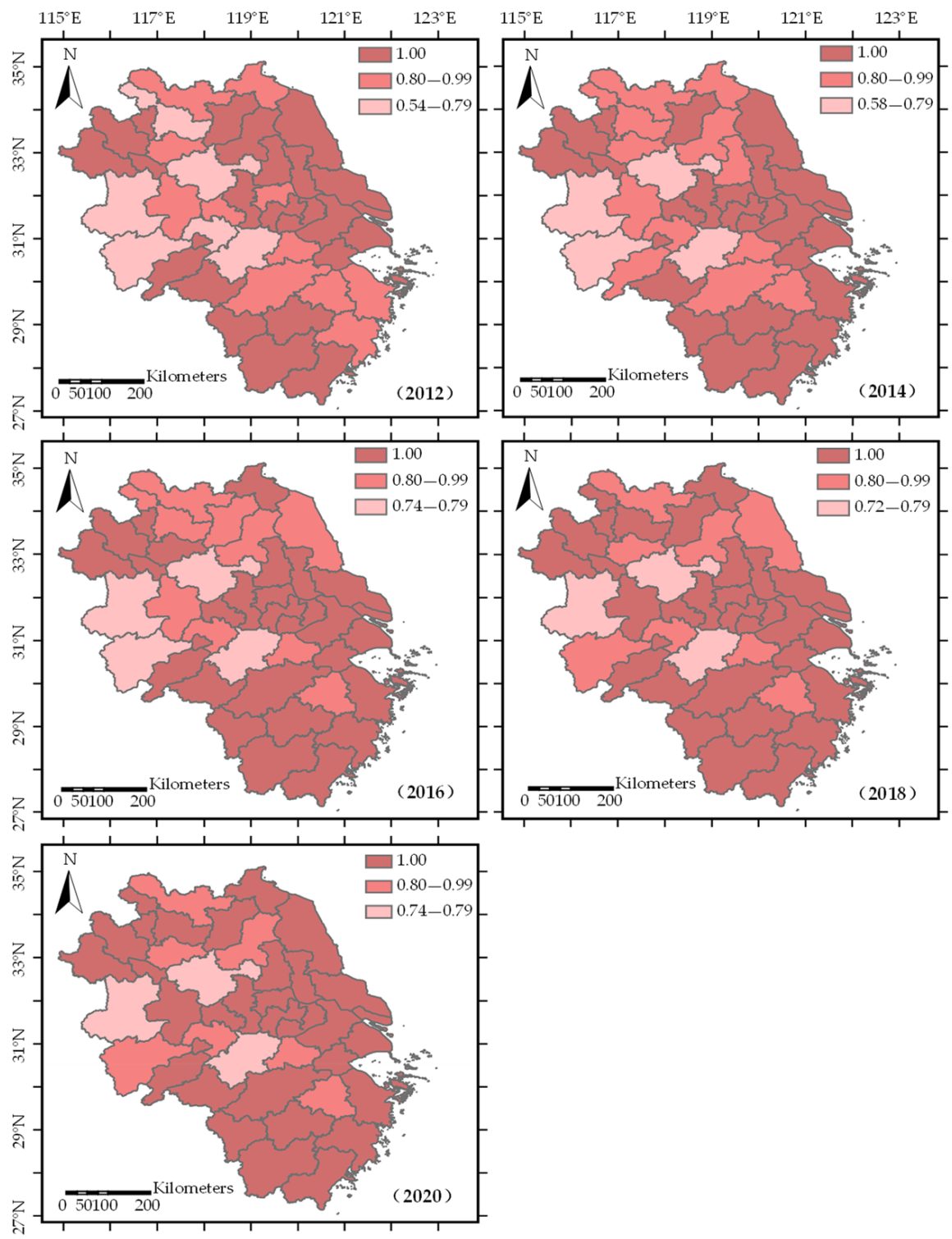

Figure 6. Spatial distribution changes in the technical utilisation efficiency of ecological land in the Yangtze Delta from 2012 to 2020.

As shown in Figure 6, the technical utilisation efficiency of ecological land in the Yangtze Delta exhibited an overall increasing trend, with few cities with efficiency remaining low. The number of cities with a technical efficiency of 1 increased from 24 to 25, 28, 
30 , and finally 31 ; the number of cities with a technical efficiency of less than 0.8 decreased from 6 to 4 and then 3 .

The lowest technical efficiency increased from 0.54 in 2012 to over 0.70 in 2020 . The technical efficiency of ecological land utilisation in Shanghai and its surrounding cities had always maintained a high level, while the technical efficiency of peripheral cities far away from Shanghai decreased, especially the technical efficiency of Lu'an, Xuancheng, and Chuzhou, all in Anhui, remained lower than 0.8.

\subsubsection{Analysis of Scale Efficiency}

Equations (1)-(3) and MaxDEA Ultra7 were used to calculate the scale utilisation efficiency. The result is shown in Figure 7.
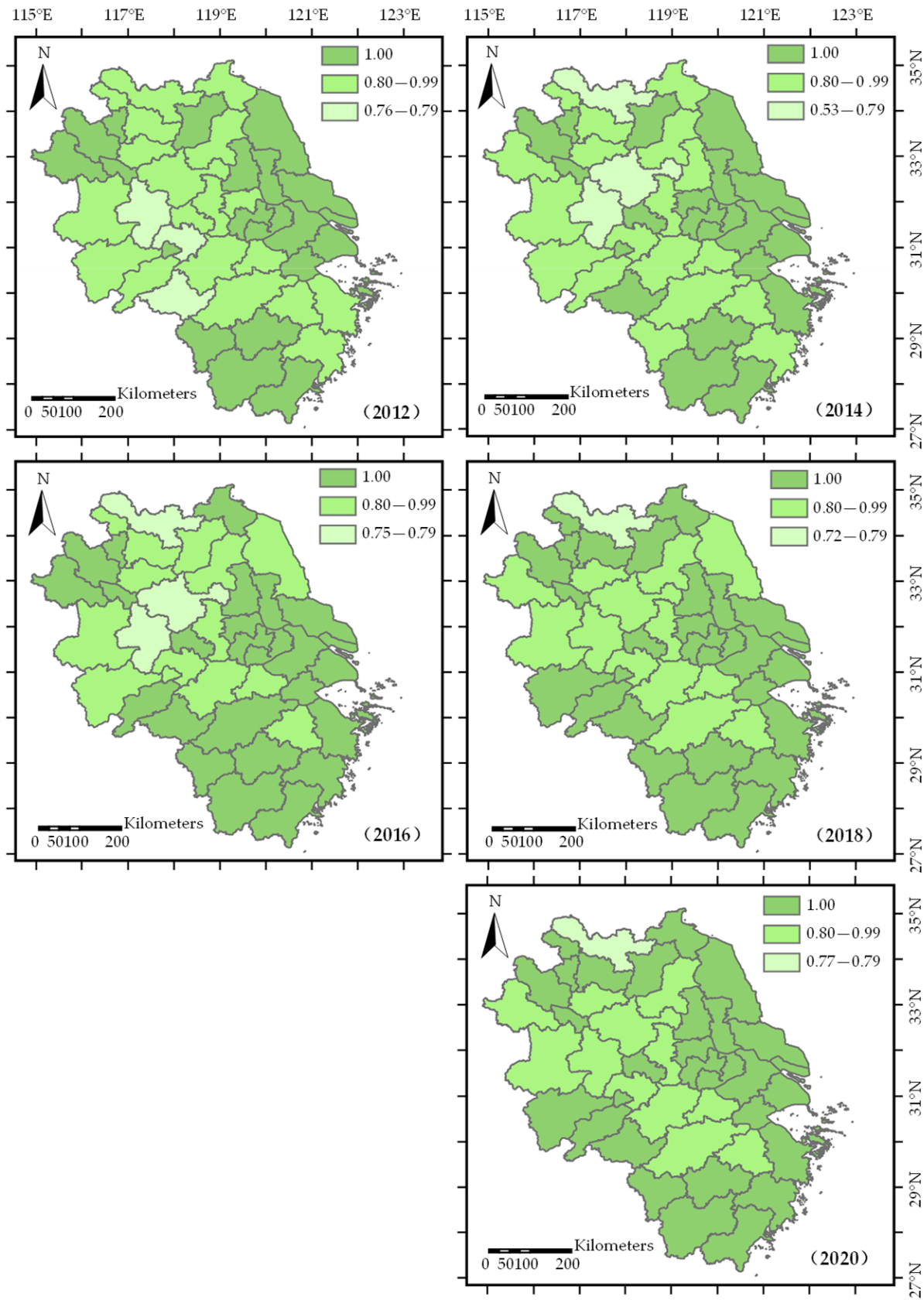

Figure 7. Spatial distribution changes in scale utilisation efficiency of ecological land in the Yangtze Delta from 2012 to 2020. 
According to Figure 7, the scale utilisation efficiency of ecological land in the Yangtze Delta presented an overall increasing trend. The number of cities with a scale efficiency of 1 increased from 20 to 28 ; the number of cities whose scale efficiency was between 0.8 and 1 decreased from 18 to 12; and that of cities with a scale efficiency less than 0.8 dropped from 3 to 1 . In 2020, all the cities had a scale efficiency of over 0.8, except Xuzhou in Jiangsu. Overall, the scale efficiency of ecological land utilisation for most cities in the Yangtze Delta maintained a high level, and only a few cities had low scale efficiency.

\subsubsection{Analysis of the Relationship between Technical and Scale Efficiency}

According to the grouping result, the relationship between the technical and scale utilisation efficiency of ecological land for all 41 cities in the Yangtze Delta in 2020 was determined (Figure 8).

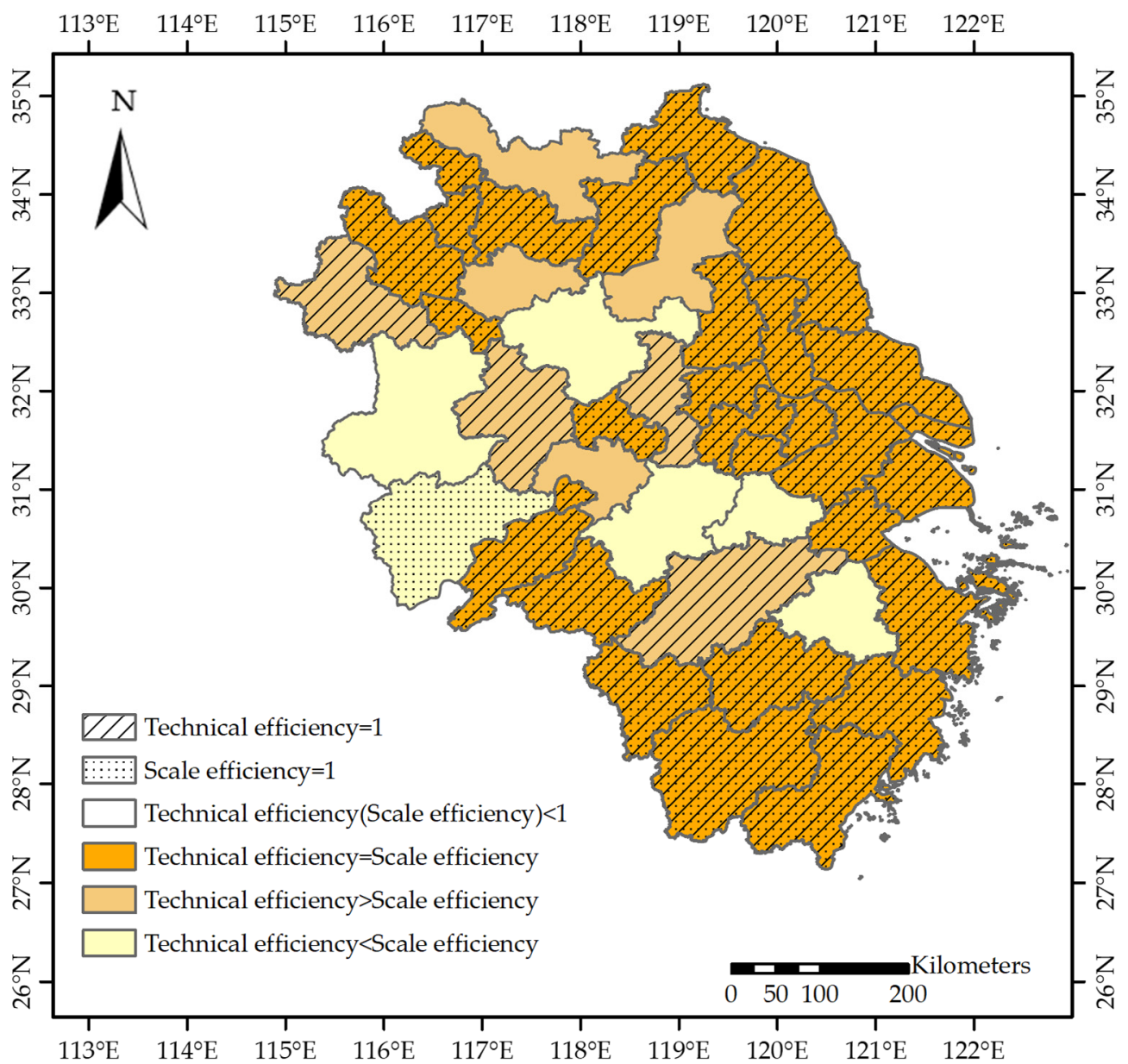

Figure 8. Relationship between the technical and scale utilisation efficiency of ecological land in the Yangtze Delta in 2020.

Figure 8 reveals five types (Types I, II, III, V, and VI) of technical efficiency-scale efficiency relationships in 2020. Twenty-seven cities were Type I, accounting for $66 \%$ of all cities; four were Type II; one was Type III; four were Type V; and five were Type VI. The technical efficiency was equal to the scale efficiency in most cities.

Cities with technical efficiency greater than scale efficiency were Nanjing, Huai'an, and Xuzhou in Jiangsu; Fuyang, Bengbu, Hefei, and Wuhu in Anhui; and Hangzhou in Zhejiang. Cities whose technical efficiency was lower than their scale efficiency were Huzhou and Shaoxing in Zhejiang; and Chuzhou, Lu'an, Anqing, and Xuancheng in Anhui. 


\subsection{Analysis of Causes and Improvement in Low Utilisation Efficiency of Ecological Land in} Yangtze Delta Cities

\subsubsection{Analysis of Causes}

This study explored the causes of low ecological land utilisation efficiency in a number of cities in the Yangtze Delta in 2020. Table 4 presents the results.

Table 4. Causes of low ecological land utilisation efficiency in Yangtze Delta cities.

\begin{tabular}{|c|c|c|c|c|c|c|c|}
\hline Province & City & $\begin{array}{l}\text { Comprehensive } \\
\text { Efficiency }\end{array}$ & $\begin{array}{l}\text { Technical } \\
\text { Efficiency }\end{array}$ & $\begin{array}{l}\text { Scale } \\
\text { Efficiency }\end{array}$ & $\begin{array}{l}\text { Returns to } \\
\text { Scale }\end{array}$ & Input Redundancy & Output Deficiency (or Excess) \\
\hline \multirow{3}{*}{ Jiangsu } & Nanjing & 0.95 & 1.00 & 0.95 & Increasing & - & \multirow{2}{*}{$\begin{array}{c}\text { Products, citizens, water quality, air } \\
\text { pollutants }\end{array}$} \\
\hline & Xuzhou & 0.63 & 0.82 & 0.77 & Increasing & Capital & \\
\hline & Huai'an & 0.73 & 0.86 & 0.85 & Increasing & $\begin{array}{l}\text { Grassland, waters, } \\
\text { capital }\end{array}$ & Products, citizens, water quality \\
\hline \multirow{3}{*}{ Zhejiang } & Hangzhou & 0.94 & 1.00 & 0.94 & Increasing & \multirow{3}{*}{$\begin{array}{c}\text { - } \\
\text { Forest, grassland, } \\
\text { labour } \\
\text { Forest, grassland, } \\
\text { capital }\end{array}$} & - \\
\hline & Huzhou & 0.92 & 0.94 & 0.98 & Increasing & & Products, citizens, water quality \\
\hline & Shaoxing & 0.87 & 0.91 & 0.96 & Increasing & & Products, citizens, water quality \\
\hline \multirow{8}{*}{ Anhui } & Hefei & 0.93 & 1.00 & 0.93 & Increasing & - & - \\
\hline & Fuyang & 0.98 & 1.00 & 0.98 & Decreasing & - & \multirow{2}{*}{$\begin{array}{c}\text { Products, citizens, water quality, air } \\
\text { pollutants }\end{array}$} \\
\hline & Bengbu & 0.97 & 0.99 & 0.98 & Decreasing & - & \\
\hline & Anqing & 0.86 & 0.86 & 1.00 & Constant & $\begin{array}{c}\text { Grassland, waters, } \\
\text { labour }\end{array}$ & Products, citizens, water quality \\
\hline & Lu'an & 0.73 & 0.74 & 0.99 & Increasing & $\begin{array}{l}\text { Forest, grassland, } \\
\text { waters, labour }\end{array}$ & Products, citizens, water quality \\
\hline & Chuzhou & 0.65 & 0.75 & 0.87 & Increasing & $\begin{array}{l}\text { Forest, grassland, } \\
\text { waters }\end{array}$ & Products, citizens, water quality \\
\hline & Wuhu & 0.79 & 0.95 & 0.83 & Increasing & $\begin{array}{l}\text { Forest, grassland, } \\
\text { capital }\end{array}$ & $\begin{array}{c}\text { Products, citizens, water quality, air } \\
\text { pollutants }\end{array}$ \\
\hline & Xuancheng & 0.69 & 0.77 & 0.90 & Increasing & Forest, grassland & Products, citizens, water quality \\
\hline
\end{tabular}

According to Table 4, technical and scale factors both contributed to a low utilisation efficiency for ecological land, and the factors varied across cities. The main reason for the low efficiency in Nanjing, Hangzhou, Hefei, and Fuyang was low scale efficiency; specifically, the scale of ecological land utilisation in Nanjing, Hangzhou, and Hefei was less than optimal, whereas that in Fuyang was larger than optimal.

The low efficiency in Anqing was attributable to input redundancy and deficiency of desirable output caused by low technical efficiency for production. For the remainder of the cities, low efficiency was caused mainly by low technical and scale efficiency; they exhibited input redundancy, deficiency of desirable output, and a suboptimal scale of ecological land utilisation. Xuzhou, Bengbu, and Wuhu, in particular, had excessive output of air pollutants. Except for Bengbu, whose scale of ecological land utilisation was larger than optimal, all the cities had a utilisation scale smaller than optimal.

\subsubsection{Analysis of Improvement}

According to the analysis of causes, the improvement of ecological land utilisation efficiency in the aforementioned cities should be focused on economical and intensive land use, innovative techniques, and optimal utilization scale. The purpose of ecological and intensive land use is to make effective use of resources by reducing the waste of resources and by coordinating the use of resources. Innovating techniques for ecological land utilisation are aimed at increasing the socioeconomic conversion of resources and reducing pollutant emissions by diversifying approaches to resource use and consolidating the industrial chain of resource use.

The aim of the optimal ecological land utilisation scale is to obtain optimal benefits through achieving the environmentally and socioeconomically optimal combination of as well as the effective operation of elements, such as labour and capital. Nanjing, Hangzhou, Hefei, and Fuyang, whose efficiency was low only in the scale aspect, should adjust their ecological land utilisation scale to a more appropriate level. Specifically, Nanjing, Hangzhou, and Hefei, which exhibited increasing returns to scale, should have their 
utilisation scale increased, whereas for Fuyang, with its decreasing returns to scale, the scale should be decreased.

The efficiency of Anqing was low only in the technical aspect, indicating a need to enhance its economical and intensive use of ecological land as well as technical innovation. The remaining nine cities, whose technical efficiency and scale efficiency were both low, should increase their efforts toward using ecological land economically and intensively, innovating techniques, and adjusting the utilisation scale to a more appropriate level; all the cities should increase their ecological land utilisation scale, except Bengbu, which should decrease its utilisation scale.

\section{Discussion}

The reduction of ecological land area and low-efficiency utilisation of ecological land aggravated the vulnerability of ecological systems $[5,7,8]$, simultaneously posing a substantial risk to the healthy development of human society [9]. In rapid-urbanization areas, due to the reduction of ecological land accompanied with a rapid increase of construction land [1] and the low-efficiency utilisation of ecological land under high-input and high-consumption extensive development mode, the problems of resource exhaustion and environmental pollution are more serious [51,54]. In this study, by taking the Yangtze Delta, the region featured by a high urbanisation level and rapid development in China as an example, the temporospatial rules of ecological land utilisation efficiency and the related causes were explored in depth.

The comprehensive efficiency is an index that can characterize the efficiency for multiple aspects, including technical and scale, which can measure the overall utilisation efficiency of ecological land. During the whole research period (2012-2020), the comprehensive efficiency of ecological land was high and showed an upward trend. This can be attributed to active economic development actions and requirements for increasing importance to economic quality development.

Unbalanced spatial distribution of comprehensive efficiency can be observed; to be specific, the comprehensive efficiency in Shanghai was the highest and decreased on the whole from Shanghai (as the centre) towards the surrounding area. In other words, the further away from Shanghai the region is, the lower the utilisation efficiency of ecological land in the region may be. This suggests that Shanghai that took the lead in reform and opening up, and its neighbour cities under great economic development radiation effects can easily achieve high-efficiency utilisation of ecological land, which is mainly due to the previous accumulation of abundant labour force, strong capita, and advanced technologies in these cities.

In order to fully and deeply explore the change rules of ecological land utilisation efficiency, both technical efficiency and scale efficiency were calculated to measure the utilisation efficiency of ecological land from the perspective of technology and scale in this study. The technical efficiency and scale efficiency both increased, which can be attributed to the technological development and the expansion of investment scale. In 2020, the technical efficiencies of three cities were below 0.8 while the scale efficiency of only one city was lower than 0.8 , suggesting a higher possibility of the enhancement of scale efficiency than that of technical efficiency. This may be due to the fact that technical progress faces greater difficulties and requires a longer period in realization.

The same year, 27 cities were equal in technical efficiencies and scale efficiencies, eight cities had greater technical efficiencies than scale efficiencies, and six cities had smaller technical efficiencies than scale efficiencies. Accordingly, the technical efficiency of ecological land utilisation did not develop synchronously with the scale efficiency, which may be related to the different advantageous resources of different cities. For example, some cities possess advanced technologies and a moderate investment scale while some cities only have one of the above advantageous conditions.

The cities with low ecological land utilisation efficiencies in the Yangtze Delta were selected for projection analysis to reveal the detailed reasons of low efficiency. In 2020, the 
comprehensive efficiencies of 14 cities, including Nanjing, Xuzhou, Huai'an, Hangzhou, Huzhou, Shaoxing, Hefei, Fuyang, Bengbu, Anqing, Lu'an, Chuzhou, Wuhu, and Xuancheng, were below 1 , indicating that these cities have not reached the optimal condition in term of their ecological land utilisation efficiency.

Four cities including Nanjing, Hangzhou, Hefei, and Fuyang, had technical efficiencies of 1 and scale efficiencies of below 1, suggesting that an inappropriate investment scale can mainly account for low ecological land utilisation efficiency. Among the four cities, the sums of peer weights of the former three cities were all lower than 1 (i.e., $\sum_{j=1}^{n} \lambda_{j}<1$ ), which reflected that ecological land utilisation was at a stage of increasing returns to scale and that the current investment scales were too small.

The sum of the peer weights of Fuyang exceeded 1 (i.e., $\sum_{j=1}^{n} \lambda_{j}>1$ ), which reflected that the ecological land utilisation was at a stage of decreasing returns to scale and that the current investment scales were too great. The scale efficiency of Anqing equalled 1 while its technical efficiency was lower than 1 , indicating that the low ecological land utilisation efficiency of Anqing should be attributed to the low technological level, and accordingly, the invested grasslands, water areas, and labour have not been adequately utilised while the products, urban residents, and water quality were short in output.

For the remaining nine cities, including Xuzhou, Huai'an, Huzhou, Shaoxing, Bengbu, Lu'an, Chuzhou, Wuhu, and Xuancheng, both the technical efficiencies and the scale efficiencies were below 1 , which were the result of the combined action of a low technological level and inappropriate investment scale. In addition to the inadequate utilisation of input resources and insufficient expected output, excess air pollutant output also appeared in Xuzhou, Bengbu, and Wuhu. Some scholars also drew similar conclusions [71] that low ecoeconomics can be mainly attributed to an unreasonable production scale and substandard production technology, thereby, leading to resource investment redundancy, insufficient output of the number of days with good air quality, and excess $\mathrm{PM}_{2.5}$ output.

Without adequate countermeasures, the reduction of ecological land area and inefficient utilisation of ecological land will bring about greater risk to human health, ecological system, society, and economy [10]. Through the above analysis, temporospatial distribution patterns of ecological land utilisation efficiency and the related reasons for low efficiency can be clarified, and then accurate improvement measures can be proposed. The intensive and economical utilisation of ecological land is an important countermeasure for various cities to enhance their utilisation efficiency.

Additionally, Nanjing, Hangzhou, and Hefei should strengthen the construction with an adequate investment scale; Anqing should strengthen the utilisation of technological innovations; Xuzhou, Huai'an, Huzhou, Shaoxing, Bengbu, Lu'an, Chuzhou, Wuhu, and Xuancheng should strengthen both the construction with an adequate investment scale and the utilisation of technological innovations.

As the utilisation of ecological land in the Yangtze Delta increases in both intensity and density, problems, mainly including soil pollution, geological disasters, and extreme weather, may be increasingly prominent. For example, will soil pollution, geological disasters and extreme weather will affect the sustainable utilisation of ecological land? If the effects exist, how best to deal with it? These problems deserve further investigation to ensure the future of the Yangtze Delta.

According to the present research results, the utilisation efficiency of ecological land in the Yangtze Delta increased overall as shown in Figure 9. Gaining a full understanding of the temporospatial distribution rules of ecological land utilisation efficiency and the causes of low efficiency is important for adopting accurate countermeasures to enhance the utilisation efficiency, thereby, improving the ecological crises, including resource shortages and the environmental pollution induced by rapid urbanization. The present study can provide an important basis for studying the high-efficiency utilisation of ecological land in China's Yangtze Delta and similar regions. 


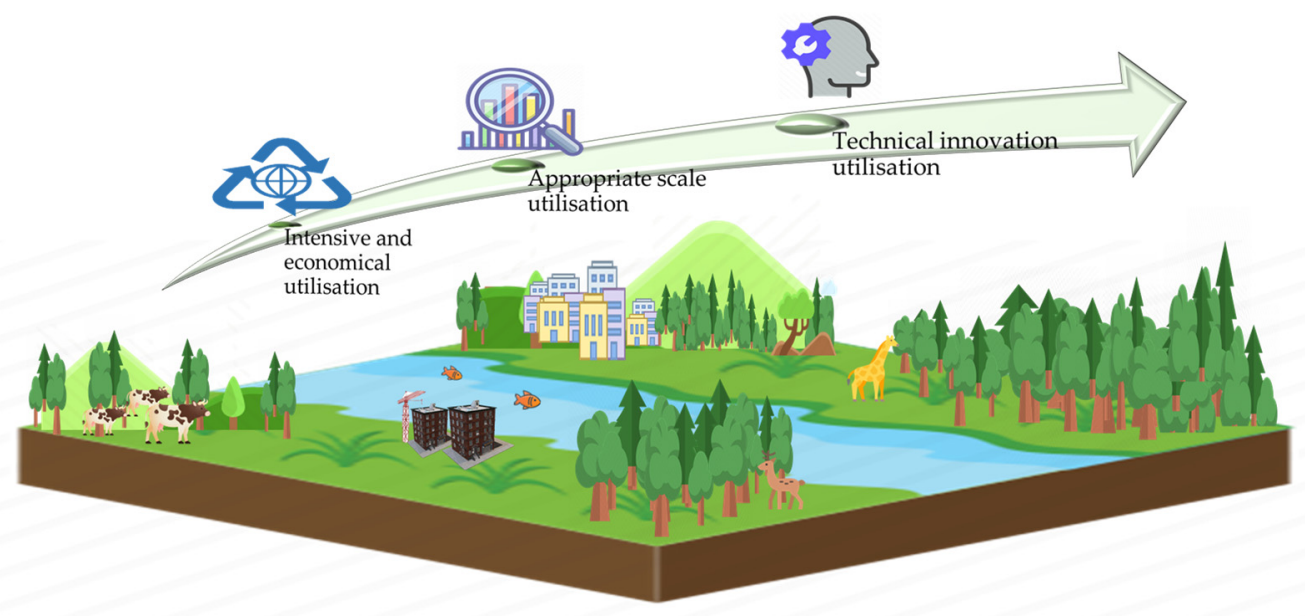

Figure 9. Schematic diagram of the ecological land utilisation efficiency in the Yangtze Delta.

\section{Conclusions}

The low efficiency of ecological land utilisation is more harmful to human health than the reduction of ecological land area, especially in areas with rapid urbanization. In this study, by performing a case study in the Yangtze Delta, the characteristics of ecological land utilisation efficiency, and the causes of low utilisation efficiency were explored. Finally, accurate countermeasures were put forward. The main conclusions can be summarized as follows:

1. Overall, the comprehensive utilisation efficiency of ecological land in the Yangtze Delta was high and exhibited an increasing trend with fluctuations. Cities in the Yangtze Delta were classified as high-efficiency, medium-efficiency, or poor-efficiency types according to the comprehensive efficiency. High-efficiency cities were mainly distributed in Shanghai and the surrounding areas, and poor-efficiency ones were observed mainly in Anhui and the north of Jiangsu, which were relatively distant from Shanghai. The number of high-efficiency cities increased gradually, whereas that of medium- and poor-efficiency cities exhibited a gradual decrease.

2. The technical efficiency and scale efficiency of ecological land in the Yangtze Delta exhibited overall increasing trends. The technical efficiency of Lu'an, Xuancheng, and Chuzhou in Anhui were consistently low, as was the scale efficiency of Xuzhou in Jiangsu. According to the relationship between their technical and scale efficiency, cities in the Yangtze Delta were categorised into five types. Specifically, 27 cities, including Shanghai, fell under Type I; Nanjing and three other cities were under Type II; Anqing was under Type III; Xuzhou and three others were under Type V; and Lu'an and four others were under Type VI.

3. Nanjing and 13 other cities exhibited poor ecological land utilisation efficiency, and their low efficiency were attributable to low technology, an improper investment scale, or both. Anqing's low efficiency generally resulted from the insufficient utilisation of input resources and deficiency of desirable output caused by technical inefficiency. The low efficiency of Nanjing and three other cities was predominantly caused by an excessively large or small investment scale. For the remainder, low efficiency was due to the presence of an inappropriate investment scale along with input resources with insufficient utilisation or output deficiency (excess).

4. Improvement of the ecological land utilisation efficiency in the Yangtze Delta should be focused on the economical and intensive use of the land, technical innovations, and optimal investments. Anqing should enhance its economical and intensive use of ecological land and innovate related techniques. Nanjing and three other cities should focus on adjusting their ecological land investment scale to a more appropriate 
level. The remaining cities should enhance their economic and intensive use of ecological land while innovating their techniques and adjusting the investment scale of such land.

Author Contributions: Conceptualization, C.Z.; Data curation, Z.F.; Formal analysis, C.Z.; Funding acquisition, C.Z.; Investigation, Z.F. and W.-L.H.; Methodology, C.Z.; Project administration, C.Z.; Resources, Q.R.; Software, Q.R.; Supervision, C.Z.; Writing-review and editing, W.-L.H. All authors have read and agreed to the published version of the manuscript.

Funding: This research was funded by "Humanities and Social Sciences Foundation of the Chinese Ministry of Education, grant number 20YJA630087; 20YJAGAT002", Innovation and entrepreneurship training program for university student in Jiangsu Province, grant number 202010323030Y".

Institutional Review Board Statement: Not applicable.

Informed Consent Statement: Not applicable.

Data Availability Statement: The data presented in this study are available on request from the corresponding author.

Conflicts of Interest: The authors declare no conflict of interest.

\section{References}

1. Fernández Martínez, P.; de Castro-Pardo, M.; Barroso, V.M.; Azevedo, J.C. Assessing Sustainable Rural Development Based on Ecosystem Services Vulnerability. Land 2020, 9, 222. [CrossRef]

2. Hsu, W.-L.; Shen, X.; Xu, H.; Zhang, C.; Liu, H.-L.; Shiau, Y.-C. Integrated Evaluations of Resource and Environment Carrying Capacity of the Huaihe River Ecological and Economic Belt in China. Land 2021, 10, 1168. [CrossRef]

3. Garrity, E.J. Using Systems Thinking to Understand and Enlarge Mental Models: Helping the Transition to a Sustainable World. Systems 2018, 6, 15. [CrossRef]

4. Zhou, Y.; Chen, Y.; Hu, Y. Assessing Efficiency of Urban Land Utilisation under Environmental Constraints in Yangtze River Delta, China. Int. J. Environ. Res. Public Health 2021, 18, 12634. [CrossRef]

5. Xu, H.; Wang, C.C.; Shen, X.; Zlatanova, S. 3D Tree Reconstruction in Support of Urban Microclimate Simulation: A Comprehensive Literature Review. Buildings 2021, 11, 417. [CrossRef]

6. Remizov, A.; Tukaziban, A.; Yelzhanova, Z.; Junussova, T.; Karaca, F. Adoption of Green Building Assessment Systems to Existing Buildings under Kazakhstani Conditions. Buildings 2021, 11, 325. [CrossRef]

7. Zhang, Q.; Tang, D.; Bethel, B.J. Yangtze River Basin Environmental Regulation Efficiency Based on the Empirical Analysis of 97 Cities from 2005 to 2016. Int. J. Environ. Res. Public Health 2021, 18, 5697. [CrossRef]

8. Wang, R.; Xu, X.; Bai, Y.; Alatalo, J.M.; Yang, Z.; Yang, W.; Yang, Z. Impacts of Urban Land Use Changes on Ecosystem Services in Dianchi Lake Basin, China. Sustainability 2021, 13, 4813. [CrossRef]

9. Jellason, N.P.; Robinson, E.J.Z.; Chapman, A.S.A.; Neina, D.; Devenish, A.J.M.; Po, J.Y.T.; Adolph, B. A Systematic Review of Drivers and Constraints on Agricultural Expansion in Sub-Saharan Africa. Land 2021, 10, 332. [CrossRef]

10. Nöldeke, B.; Winter, E.; Laumonier, Y.; Simamora, T. Simulating Agroforestry Adoption in Rural Indonesia: The Potential of Trees on Farms for Livelihoods and Environment. Land 2021, 10, 385. [CrossRef]

11. Sharma, K.; Mathur, M. Identifying Climate Adjacency for Enhancing Climate Action Using Systems Thinking and Modelling. Systems 2021, 9, 83. [CrossRef]

12. Kookana, R.S.; Drechsel, P.; Jamwal, P.; Vanderzalm, J. Urbanisation and emerging economies: Issues and potential solutions for water and food security. Sci. Total Environ. 2020, 732, 139057. [CrossRef] [PubMed]

13. Atkinson, R. Alpha City: How London Was Captured by the Super-Rich; Verso Books: London, UK; New York, NY, USA, 2021.

14. Sklair, L. The Icon Project: Architecture, Cities, and Capitalist Globalization; Oxford University Press: New York, NY, USA, 2017.

15. Stein, S. Capital City: Gentrification and the Real Estate State; Verso Books: London, UK; New York, NY, USA, 2019.

16. Lees, L.; Phillips, M. Handbook of Gentrification Studies; Edward Elgar Publishing: Cheltenham, UK; Northampton, UK, 2018.

17. Grebler, L. Urban Renewal in European Countries. J. Am. Inst. Plan. 1962, 28, 229-238. [CrossRef]

18. Balletto, G.; Ladu, M.; Milesi, A.; Camerin, F.; Borruso, G. Walkable City and Military Enclaves: Analysis and Decision-Making Approach to Support the Proximity Connection in Urban Regeneration. Sustainability 2022, 14, 457. [CrossRef]

19. Elmqvist, T.; Zipperer, W.; Güneralp, B. Urbanization, habitat loss, biodiversity decline: Solution pathways to break the cycle. In Routledge Handbook of Urbanization Global Environmental Change; Karen, S., Solecki, W.D., Griffith, C.A., Eds.; Routledge: London, UK; New York, NY, USA, 2016; Volume 2016, pp. 139-151.

20. Wang, W.; Wu, T.; Li, Y.; Xie, S.; Han, B.; Zheng, H.; Ouyang, Z. Urbanization Impacts on Natural Habitat and Ecosystem Services in the Guangdong-Hong Kong-Macao "Megacity". Sustainability 2020, 12, 6675. [CrossRef]

21. Zhou, D. Examination of the 15-Minute Life Cycle Program of a Chinese Mega City: Case Study of Guangzhou. WIT Trans. Ecol. Environ. 2019, 1, 97-106. [CrossRef] 
22. Scoppa, M.; Anabtawi, R. Connectivity in Superblock Street Networks: Measuring Distance, Directness, and the Diversity of Pedestrian Paths. Sustainability 2021, 13, 13862. [CrossRef]

23. Camerin, F.; Mora, A.Á. Regenerating Bilbao: From "productive industries" to "productive services". Territorio 2019, 89, 2. [CrossRef]

24. Campbell, C.L.; Heck, W.W. An ecological perspective on sustainable development. In Principles of Sustainable Development; CRC Press: Los Angeles, CA, USA, 1997; pp. 47-67. Available online: https://www.taylorfrancis.com/chapters/edit/10.1201/978020 3742051-2/ecological-perspective-sustainable-development-lee-campbell-walter-heck (accessed on 3 November 2021).

25. Churchill, E. Environmental degradation and human well-being: Report of the millennium ecosystem assessment. Popul. Dev. Rev. 2005, 31, 389-398. Available online: https://www.jstor.org/stable/3401377 (accessed on 3 November 2021).

26. Gu, Y.; Wu, Y.; Liu, J.; Xu, M.; Zuo, T. Ecological civilization and government administrative system reform in China. Resour. Conserv. Recycl. 2020, 155, 104654. [CrossRef]

27. Jha, R.K.; Kalita, P.K.; Cooke, R.A.; Kumar, P.; Davidson, P.C.; Jat, R. Predicting the Water Requirement for Rice Production as Affected by Projected Climate Change in Bihar, India. Water 2020, 12, 3312. [CrossRef]

28. Vu, A.V.; Hortle, K.G.; Nguyen, D.N. Factors Driving Long Term Declines in Inland Fishery Yields in the Mekong Delta. Water 2021, 13, 1005. [CrossRef]

29. Fiore, N.V.; Ferreira, C.C.; Dzedzej, M.; Massi, K.G. Monitoring of a Seedling Planting Restoration in a Permanent Preservation Area of the Southeast Atlantic Forest Biome, Brazil. Forests 2019, 10, 768. [CrossRef]

30. Huang, C.; Yin, K.; Liu, Z.; Cao, T. Spatial and Temporal Differences in the Green Efficiency of Water Resources in the Yangtze River Economic Belt and Their Influencing Factors. Int. J. Environ. Res. Public Health 2021, 18, 3101. [CrossRef]

31. Wang, Z.; Cao, J. Assessing and Predicting the Impact of Multi-Scenario Land Use Changes on the Ecosystem Service Value: A Case Study in the Upstream of Xiong'an New Area, China. Sustainability 2021, 13, 704. [CrossRef]

32. Foley, J.A.; De Fries, R.; Asner, G.P.; Barford, C.; Bonan, G.; Carpenter, S.R.; Chapin, F.S.; Coe, M.T.; Daily, G.C.; Gibbs, H.K. Global consequences of land use. Science 2005, 309, 570-574. [CrossRef]

33. Saaty, T.L. Fundamentals of Decision Making and Priority Theory with the Analytical Hierarchy Process; RWS Publications: Pittsburgh, PA, USA, 1994; pp. 69-84.

34. Liu, X.; Wang, X.; Zhi, Y. European Union Environment Action Programme Development and Its Enlightenment to China. Environ. Prot. 2017, 20, 65-69. Available online: https://www.cnki.net/kcms/doi/10.14026/j.cnki.0253-9705.2017.20.014.html (accessed on 3 November 2021). (In Chinese).

35. Niemi, G.J.; McDonald, M.E. Application of ecological indicators. Annu. Rev. Ecol. Evol. Syst. 2004, 35, 89-111. [CrossRef]

36. Noon, B.R. Conceptual issues in monitoring ecological resources. In Monitoring Ecosystems: Interdisciplinary Approaches for Evaluating Ecoregional Initiatives; Island Press: London, UK, 2003; pp. 27-72.

37. Liu, G.; Fu, B. The principe and characteristics of ecological regionalization. Chin. J. Environ. Eng. 1998, 6, 67-72. Available online: https://t.cnki.net/kcms/detail?v=OwXIvJq-qonEcbw2BNbP29jG51XHnqqsbLZSVSD3OCfE5_tayTfilmvzA092_N4 PLkI0J_3K19YB6M2sf8jUZ-71S13pMHyAwqsjkkbG7iOGN8qxpCee8A==\&uniplatform=NZKPT (accessed on 3 November 2021). (In Chinese).

38. Klijn, F.; de Haes, H.A.U. A hierarchical approach to ecosystems and its implications for ecological land classification. Landsc. Ecol. 1994, 9, 89-104. [CrossRef]

39. Yang, H. Analysis of local government behavior of inefficient utilization of ecological resources in China. J. Southwest Natl. Univ. (Humanit. Soc. Sci. Ed.) 2013, 34, 131-134. Available online: http://www.cqvip.com/QK/81468A/20135/45723873.html (accessed on 3 November 2021). (In Chinese).

40. Gao, J.; Li, H.; Tian, M. Concept and Significance of Ecological Assets Capitalization. J. Ecol. Rural Environ. 2016, 32, 41-46. Available online: http:/ / www.en.cnki.com.cn/Article_en/CJFDTOTAL-NCST201601009.htm (accessed on 3 November 2021). (In Chinese).

41. Watson, J.E.M.; Evans, T.; Venter, O.; Williams, B.; Tulloch, A.; Stewart, C.; Thompson, I.; Ray, J.C.; Murray, K.; Salazar, A. The exceptional value of intact forest ecosystems. Nat. Ecol. Evol. 2018, 2, 599-610. [CrossRef] [PubMed]

42. Zhang, L.; Zhou, G.; Ji, Y.; Bai, Y. Grassland carbon budget and its driving factors of the subtropical and tropical monsoon region in China during 1961 to 2013. Sci. Rep. 2017, 7, 14717. [CrossRef] [PubMed]

43. Hansen, A.T.; Dolph, C.L.; Foufoula-Georgiou, E.; Finlay, J.C. Contribution of wetlands to nitrate removal at the watershed scale. Nat. Geosci. 2018, 11, 127-132. [CrossRef]

44. An, G. Study on Spatio-temporal change of ecological land in yellow river delta based on RS\&GIS. E3S Web Conf. 2018, 38, 01008. [CrossRef]

45. Guo, Y.; Hu, Y.; Shi, K.; Bilan, Y. Valuation of Water Resource Green Efficiency Based on SBM-TOBIT Panel Model: Case Study from Henan Province, China. Sustainability 2020, 12, 6944. [CrossRef]

46. Wang, Y.; Zhang, D.; Wang, Y. Evaluation Analysis of Forest Ecological Security in 11 Provinces (Cities) of the Yangtze River Economic Belt. Sustainability 2021, 13, 4845. [CrossRef]

47. Hu, M.; Sarwar, S.; Li, Z. Spatio-Temporal Differentiation Mode and Threshold Effect of Yangtze River Delta Urban Ecological Well-Being Performance Based on Network DEA. Sustainability 2021, 13, 4550. [CrossRef]

48. Scott, M.J.; Bilyard, G.R.; Link, S.O.; Ulibarri, C.A.; Westerdahl, H.E.; Ricci, P.F.; Seely, H.E. Valuation of ecological resources and functions. Environ. Manag. 1998, 22, 49-68. [CrossRef] 
49. Straton, A. A complex systems approach to the value of ecological resources. Ecol. Econ. 2006, 56, 402-411. [CrossRef]

50. Mäler, K.-G. Development, ecological resources and their management: A study of complex dynamic systems. Eur. Econ. Rev. 2000, 44, 645-665. [CrossRef]

51. Zhang, K.; Ma, J.; Wu, Z.; Bian, L. Assessment of water resources utilization efficiency of 11 provinces(cities) in Changjiang Economic Belt. Yangtze River 2015, 46, 48-51. Available online: https://t.cnki.net/kcms/detail?v=OwXIvJq-qolKHtyumc1 KdAcC5P6Cy7cFdpnE6oITuPjGLO9Ek75bNEwhnw0K2p01g9whqjgoRCz73QFqFpSsy-KmFliNovEC6dUqPBeFYZzD_jfHa5 CTildiJByDEZxm\&uniplatform $=$ NZKPT (accessed on 3 November 2021). (In Chinese).

52. Gao, Y.; Xu, X.; Wang, H.; Gao, X.; Yin, X. New model for water use efficiency evaluation of China and its application. Syst. Eng. Theory Pract. 2013, 33, 776-784. Available online: https://t.cnki.net/kcms/detail?v=OwXIvJq-qonZ9klTYgwh2ljUsf6 6QJIVh08nOJfaSBS7uMsdGARGCTp9s_IGE_Lqm4JB6agH-sFZRR3Y_n8VNQA_psgXfpM48mnlkpO8lemIDelGyf4UQQ==\& uniplatform $=$ NZKPT (accessed on 3 November 2021). (In Chinese).

53. Zhou, X.; Lv, G. Study on Spatial and Temporal Difference of Agricultural Eco-efficiency in Xinjiang and Its Influencing Factors: Based on The DEA-Malmquist Index-Tobit Model Analysis. J. Cent. South Univ. For. Technol. (Soc. Sci.) 2018, 12, 37-45. Available online: http:/ / qikan.cqvip.com/Qikan/Article/Detail?id=7001009955\&from=Qikan_Search_Index (accessed on 3 November 2021). (In Chinese).

54. Zhu, Q.; Chen, Y.; Hu, W.; Mei, Y. Spatiotemporal pattern of coupling coordination degree between land intensive use and regional ecological efficiency in China. Trans. Chin. Soc. Agric. Eng. 2020, 36, 234-243. (In Chinese) [CrossRef]

55. Sheng, Z.; Zhu, Q.; Wu, G. DEA Theory, Method and Application; Science Press: Beijing, China, 1996; Available online: https:/ / baike.baidu.com/item/DEA \%E7\%90\%86\%E8\%AE\%BA \%E3\%80\%81\%E6\%96\%B9\%E6\%B3\%95\%E4\%B8\%8E\%E5 \%BA \%94\%E7\%94\%A8/53089145?fr=aladdin (accessed on 3 November 2021). (In Chinese)

56. Lu, C.; Wang, D.; Li, H.; Cheng, W.; Tang, X.; Liu, W. Measurement of the Degree of Coordination in Regard to Carbon Emissions, Economic Development, and Environmental Protection in China. Appl. Sci. 2021, 11, 1750. [CrossRef]

57. Sueyoshi, T.; Ryu, Y.; Yun, J.-Y. COVID-19 Response and Prospects of Clean/Sustainable Energy Transition in Industrial Nations: New Environmental Assessment. Energies 2021, 14, 1174. [CrossRef]

58. Wang, C.-N.; Nguyen, H.-P.; Chang, C.-W. Environmental Efficiency Evaluation in the Top Asian Economies: An Application of DEA. Mathematics 2021, 9, 889. [CrossRef]

59. The Central Committee of the Communist Party of China and the State Council Issued the Outline of the Plan for Regional Integration and Development of the Yangtze River Delta. Available online: http:/ /www.gov.cn/zhengce/2019-12/01/content_ 5457442.htm (accessed on 3 November 2021).

60. Yu, F.; Li, X.; Zhang, L.; Xu, W.; Fu, R.; Wang, H. Study of ecological land in China: Conception, classification, and spatialtemporal patter. Acta Ecol. Sin. 2015, 35, 4931-4943. Available online: https://t.cnki.net/kcms/detail?v=3uoqIhG8C44YLT1OAiTRKibYlV5 Vjs7ir5D84hng_y4D11vwp0rrtVUG-_3cNXW8ZRFanJRpmYOFEXzlEk7deWLLG20RWrYw\&uniplatform=NZKPT (accessed on 3 November 2021). (In Chinese).

61. Lee, Y.-C.; Shiau, Y.-C.; Hsu, W.-L. Applying interpretive structure modeling on the interactive correlations on factor analysis in natural and cultural scenic area at Taiwan. Artif. Life Robot. 2016, 21, 37-42. [CrossRef]

62. Long, H.; Liu, Y.; Li, T.; Wang, J.; Liu, A. A Primary Study on Ecological Land Use Classification. Ecol. Environ. Sci. 2015, $24,1-7$. Available online: https://t.cnki.net/kcms/detail?v=3uoqIhG8C44YLTlOAiTRKibYlV5Vjs7ir5D84hng_y4D11vwp0rrteJjKxwZ3 OK6DkKSaXB2_w5B5SG6LAqUnjB3GMIzQy0Z\&uniplatform=NZKPT (accessed on 3 November 2021). (In Chinese).

63. Zhang, Q.; Song, C.; Chen, X. Effects of China's payment for ecosystem services programs on cropland abandonment: A case study in Tiantangzhai Township, Anhui, China. Land Use Policy 2018, 73, 239-248. [CrossRef]

64. Li, S.; Li, X.; Sun, L.; Cao, G.; Fischer, G.; Tramberend, S. An estimation of the extent of cropland abandonment in mountainous regions of China. Land Degrad. Dev. 2018, 29, 1327-1342. [CrossRef]

65. Adams, M.A.; Ghaly, A.E. An integral framework for sustainability assessment in agro-industries: Application to the Costa Rican coffee industry. Int. J. Sustain. Dev. World Ecol. 2006, 13, 83-102. [CrossRef]

66. Ma, J.; Shen, S.; ZhuGe, H. The current situation of water environmental monitoring and its analysis in China. China's Natl. Cond. Natl. Strength 2019, 7, 58-61. (In Chinese) [CrossRef]

67. Hsu, W.-L.; Tsai, F.-M.; Shiau, Y.-C. Planning and assessment system for light rail transit construction in Taiwan. Microsyst. Technol. 2021, 27, 1051-1060. [CrossRef]

68. Lu, Y.; Zhang, C.; Li, H.; Ren, Q.; Wang, M. Study on the Establishment of Ecological Economic Sustainability Assessment Indicators. In Proceedings of the 3rd Eurasian Conference on Educational Innovation 2020 (ECEI 2020), Ha Long Bay, Vietnam, 5-7 February 2020. [CrossRef]

69. Wu, Y.; Liu, X.; Guo, Y. Quantitative Methods in Economic Management; Economic Science Press: Beijing, China, 2008; Available online: https: / / baike.baidu.com/item/\%E7\%BB\%8F\%E6\%B5\%8E\%E7\%AE\%A1\%E7\%90\%86\%E4\%B8\%AD\%E7\%9A\%84\%E6 $\% 95 \%$ B0\%E9\%87\%8F\%E6\%96\%B9\%E6\%B3\%95/8095804?fr=aladdin (accessed on 3 November 2021). (In Chinese) 
70. Zhou, S. Earnestly implement the spirit of the 7th Environmental Protection Congress and meet the 18th National Congress of the Communist Party of China with outstanding results-Speech at the 2012 National Conference on Environmental Protection. Environ. Educ. 2012, 1, 18-27. Available online: https://t.cnki.net/kcms/detail?v=OwXIvJq-qonKeliytQKckruzscMXvpQBmZea0cHDrjq4_N6xbA_ssGzWNW-xHqA9F3R7itNfzp8ZD57jMKNJ5Fk0zWIZqCkIS4jSsDOumVd35S_ooaYA= $=$ \&uniplatform $=$ NZKPT (accessed on 3 November 2021). (In Chinese).

71. Zhang, C.; Wang, C.; Mao, G.; Wang, M.; Hsu, W.-L. An Empirical Study on the Ecological Economy of the Huai River in China. Water 2020, 12, 2162. [CrossRef] 